\title{
A Study on Miracles through Holy Bible using Neutrosophic Cognitive Maps (NCMs)
}

\author{
A. Victor Devadoss \\ Professor \\ Loyola College \\ Chennai -600034
}

\author{
A.Rajkumar \\ Assistant Professor \\ Hindustan University \\ Chennai - 603103
}

\author{
N.Jose Parvin Praveena \\ Assistant Professor \\ KCG College of Technology, \\ Chennai -600097
}

\begin{abstract}
This paper aims at studying at length the various reasons for miracles with incidents from the Holy Bible adopting the Neutrosophic Cognitive Maps, a generalization of Fuzzy Cognitive Maps. The content gives preliminaries of FCM and NCM with a descriptive account of the problem and the various miracles witnessed in the Bible using NCM. The data acquired is collated to conclude on the most essential component that results in the discharge of miracles in various instances.
\end{abstract}

Index Terms - Fuzzy cognitive maps, Neutrosophic Cognitive Maps, Unsupervised, Bible.

\section{INTRODUCTION}

A Miracle is an event that apparently contradicts known scientific laws and is hence thought to be due to supernatural causes especially to an act of god. Miracles in the new testament had a purpose - miracles were performed to confirm the word ( Mark 16:20), to create faith in Jesus Christ ( John 20:30-31), to demonstrate that God is with Jesus ( John 3:2), to prove that Jesus is the Christ, the Son of God, as prophesied (Matt 8:16-17). The New Testament narrates about thirty five miracles performed by Jesus. These miracles can be classified as Miracles of nature, Miracles of healing, and Miracles of resurrection. These miracles are listed below:

Calming the storm Feeding five thousand

Walking on water

Feeding four thousand

Coin in fish's mouth

Fig tree withered

Catch of fish

Water into wine

Another catch of fish

Cleansing of a Leper

Centurion's servant

Peter's mother-in-law

Paralyzed man

Woman with hemorrhage

Man with withered hand

Two blind men

Canaanite woman

Blind Bartimaeus

Blind man at Bethsaida

Deaf and mute man

Crippled woman

Man with dropsy

lepers

Malchus's ear
( Matthew 8:23-27 )

(Matthew 14:13-21)

(Matthew 14:22-33)

( Matthew 15:32-38)

( Matthew 17:24-27)

( Matthew 21:22)

( Luke 5:1-11)

( John 2:1-11)

( John 21:1-11)

( Matthew 8:2-4)

( Matthew 8:5-13)

( Matthew 8:14-15)

( Matthew 9:2-8)

( Matthew 9:20-22)

( Matthew 12:10-13)

(Matthew 9:27-31)

( Matthew 15:21-28)

( Matthew 20:29-34)

( Mark 8:22-26)

( Mark 7:32-37)

( Luke 13:11-13)

( Luke 14:1-4)

( Mark 7:11-19)

( Mark 22:50-51)
Capernaum Official's son

Sick at pool of Bethesda

Man blind from birth

Multiple demon possessed man

Gerasene demoniac

Possessed man

Possessed Blind Mute man

Epileptic boy

Possessed man

Widow's son

Jairus' daughter

Rise of Lazarus

\author{
( John 4:46-54) \\ ( John 5:1-15) \\ ( John 9:1-4) \\ ( Matthew 8:16-17) \\ (Matthew 8:28-34) \\ ( Matthew 9:32-34) \\ ( Matthew 12:22-23) \\ ( Matthew 17:14-21) \\ ( Mark 1:23-26) \\ ( Luke 7:11-17) \\ ( Matthew 9:18-19) \\ ( John 11:1-44) [1]
}

This work is based on expert opinion collected throughout Chennai. The data was collected and assimilated from the people using a linguistic questionnaire and this linguistic was transformed into fuzzy data. In this paper, the Neutrosofic Cognitive Maps(NCMs) created by Florentine Smarandache[2,] is used, which is the extension or combination of the Fuzzy Cognitive Maps(FCMs) in which indeterminacy is included. It has also become very essential that the notion of Neutrosophic logic plays a vital role in several of the real time world problems like law, IT, Stocks and Share etc. It is important to note that, while doing fuzzy mathematical models, the fuzzy matrix make take its entries from the interval [-1.1]. Even then, they are known as fuzzy matrices. Therefore, it is understood that Fuzzy tools alone have the capacity to analyze these concepts further substantiating the choice of this method. The Imperative reasons for miracles through Holy Bible using Neutrosofic Cognitive Maps, which is the generalization of Fuzzy Cognitive Maps, was defined by Dr.W.B.Vasantha Kandasamy and Florentine Smarandache. This paper consists of five sections. First Section gives the information about development of Fuzzy Cognitive Maps and Neutrosofic Cognitive Map. Second Section gives the Preliminaries of FCM and NCM. In Section three, we give the description of the problem i.e. in section three we explain about the mirales in bible using NCM. Final Section gives the Conclusion based on our study.[3]

\section{Preliminaries}

Fuzzy Cognitive Maps (FCMs) are more applicable when the data in the first place is an unsupervised one. The FCMs work is based on the opinion of the experts. FCMs model the world as a collection of classes and casual relations between classes. 


\section{Definition 2.1}

A NCMs is a directed graph with concepts like policies, events, etc, as nodes and casualities as edges. It represents casual relationship between concepts.

\section{Definition 2.2}

When the nodes of the NCM are fuzzy sets then they are called as fuzzy nodes.

\section{Definition 2.3}

A NCMS with edge weights or casualities from the set $\{-1,0$, $1, \mathrm{I}\}$ are called simple NCMs.

\section{Definition 2.4}

Let $\mathrm{C}_{\mathrm{i}}$ and $\mathrm{C}_{\mathrm{j}}$ denote the two nodes of the NCM. The directed edge from $C_{i}$ to $C_{j}$ denotes the casuality $C_{i}$ on $C_{j}$ called connections. Every edge in the NCM is weighted with a number in the set $\{-1,0,1, I\}$. Let $e_{i j}$ be the weight of the directed edge $\mathrm{C}_{\mathrm{i}} \mathrm{C}_{\mathrm{j}}$, eij $€\{-1,0,1, \mathrm{I}\}$. $\mathrm{e}_{\mathrm{ij}}=0$ if $\mathrm{C}_{\mathrm{i}}$ does not have any effect on $C_{j}, e_{i j}=1$ if increase (or decreases) in $C_{i}$ causes decrease(or increase) in $\mathrm{C}_{\mathrm{j}}, \mathrm{e}_{\mathrm{ij}}=\mathrm{I}$ if the relation or effect of $C_{i}$ on $C_{j}$ is an indeterminate.

\section{Definition 2.5}

Let $\mathrm{C}_{1}, \mathrm{C} 2, \ldots \ldots, \mathrm{C}_{\mathrm{n}}$ be nodes of a NCM. Let the neutrosofic matrix $\mathrm{N}(\mathrm{E})$ be defined as $\mathrm{N}(\mathrm{E})=(\mathrm{eij})$ where $\mathrm{e}_{\mathrm{ij}}$ is the weight of the directed edge $C_{i} C_{j}$, where $e_{i j} \in\{-1,0,1, I\}$. N (E) is called the netrosofic adjacency matrix of the NCM.

\section{Definition 2.6}

Let $\mathrm{C}_{1}, \mathrm{C} 2, \ldots \ldots, \mathrm{C}_{\mathrm{n}}$ be nodes of an NCM.

Let $A=\left\{a_{1}, a 2, \ldots \ldots\right.$, an $\}$ where $a_{i} \in\{0,1, I\}$. A is called the instantaneous state neutrosophic vector and it denotes the onoff -indeterminate state position of the node at an instant

$a_{i}=0$ if $a_{i}$ is off(no effect)

$a_{i}=1$ if $a_{i}$ is on(has effect)

$a_{i}=I$ if $a_{i}$ is indeterminate(effect cannot be determined) for $\mathrm{i}=1,2, \ldots, \mathrm{n}$.

\section{Definition 2.7}

Let $C_{1}, C_{2}, \ldots \ldots, C_{n}$ be nodes of a FCM.

Let $\overrightarrow{\mathrm{C}_{1} \mathrm{C}_{2}}, \mathrm{C}_{2} \overrightarrow{\mathrm{C}_{3}}, \ldots \ldots \ldots \mathrm{C}_{\mathrm{i}} \overrightarrow{\mathrm{C}_{\mathrm{j}}}$ be the edges of NCM. Then the edges form a directed cycle. An NCM is said to be cyclic if it possesses a directed cycle. An NCM is said to be acyclic if it does not possess any directed cycle.

\section{Definition 2.8}

An NCM with cycles is said to have a feedback. When there is a feedback in the NCM.i.e when the casual relations flow through a cycle in a revolutionary manner the NCM is called a dynamical system.

\section{Definition 2.9}

Let $\quad \overrightarrow{\mathrm{C}_{1} \mathrm{C}_{2}}, \overrightarrow{\mathrm{C}_{2} \mathrm{C}_{3}}, \ldots \ldots \ldots . \overrightarrow{\mathrm{C}_{n-1} \mathrm{C}_{\mathrm{n}}}$ be cycle, when $\mathrm{C}_{\mathrm{i}}$ is switched on and if the casuality flow through the edges of a cycle and if it again causes $C_{i}$, say that the dynamical system goes round and round. This is true for any node $\mathrm{C}_{\mathrm{i}}$, for $\mathrm{i}=$ $1,2, \ldots \ldots$ the equilibrium state for this dynamical system is called the hidden pattern.

\section{Definition 2.10}

If the equilibrium state of a dynamical system is a unique state vector, then it is called a fixed point. Consider the NCM with $\mathrm{C}_{1}, \mathrm{C}_{2}, \ldots \ldots, \mathrm{C} 9$ as nodes . For example let us start the dynamical system by switching on $\mathrm{C}_{1}$. Let us assume that the NCM settles down with $C_{1}$ and $C_{n}$ on i.e. the state vector remain as $(1,0,0, \ldots \ldots, 1)$ this neutrosophic state vector $(1,0,0, \ldots \ldots, 1)$ is called the fixed point.

\section{Definition 2.11}

If the NCM settles with a neutrosophic state vector repeating in the form

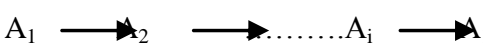

then this equilibrium is called a limit cycle of the NCM.

\section{Definition 2.12}

Finite number of NCMs can be combined together to produce the joint effect of all NCMs. If $\mathrm{N}\left(\mathrm{E}_{1}\right), \mathrm{N}\left(\mathrm{E}_{2}\right), \ldots \ldots \ldots, \mathrm{N}\left(\mathrm{E}_{\mathrm{P}}\right)$ be the neutrosophic adjacency matrices of a NCM with nodes $\mathrm{C}_{1}, \mathrm{C}_{2} \ldots . . \mathrm{C}_{\mathrm{n}}$ then the combined NCM is got by adding all the neutrosophic adjacency matrices $\mathrm{N}\left(\mathrm{E}_{1}\right), \mathrm{N}\left(\mathrm{E}_{2}\right), \ldots \ldots \ldots$, $\mathrm{N}\left(\mathrm{E}_{\mathrm{P}}\right)$. We denote the combined NCMs adjacency neutrosophic matrix by $\mathrm{N}(\mathrm{E})=\mathrm{N}\left(\mathrm{E}_{1}\right)+\mathrm{N}\left(\mathrm{E}_{2}\right)+\ldots \ldots \ldots+\mathrm{N}$ $\left(\mathrm{E}_{\mathrm{P}}\right) \cdot[4]$

\section{Method of Determination of Hidden Pattern}

Let $\left\{\mathrm{C}_{1}, \mathrm{C}_{2} \ldots \ldots \mathrm{C}_{\mathrm{n}}\right\}$ be nodes of an NCM, with feedback. Let $\mathrm{E}$ be the associated adjacency matrix. Let us find the hidden pattern when $\mathrm{C}_{1}$ is switched on when an input is given as the vector $A_{1}=(1,0,0, \ldots . .0)$, the data should pass through the neutrosophic matrix $N(E)$, this is done by multiplying $A_{1}$ by the matrix $\mathrm{N}(\mathrm{E})$

Let $\mathrm{A}_{1} \mathrm{~N}(\mathrm{E})=\left\{\mathrm{a}_{1}, \mathrm{a}_{2}, \ldots \mathrm{a}_{\mathrm{i}} \ldots, \mathrm{a}_{\mathrm{n}}\right\}$ with the threshold operation that is by replacing $a_{i}$ by 1 if $a_{i}>k$ and $a_{i}$ by 0 if $a_{i}<k(k-a$ suitable positive integer) and $a_{i}$ by $I$ if $a_{i}$ is not a integer. We update the resulting concept; the concept $\mathrm{C}_{1}$ is included in the updated vector by $\mathrm{m}$

\section{Adaptation of Neutrosofic Cognitive Maps to the Miracles}

Here, the dynamical system by a very simple model for the reasons of miracles from the Bible is illustrated. At the first stage, the following nine arbitrary attributes $\left(\mathrm{C}_{1}, \mathrm{C}_{2}, \ldots, \mathrm{C}_{9}\right)$ are 
taken. It is not mandatory to consider only nine attributes but one can increase or decrease the number of attributes according to requirement. The following attributes are taken as the main nodes for study:

Using the linguistic questionnaire and the experts' opinions the following nine concepts have been identified and taken for the study, ie $\left\{\mathrm{C}_{1}, \mathrm{C}_{2}, \ldots, \mathrm{C}_{9}\right\}$.

The concepts given below are taken as the main nodes for our problem:

\begin{tabular}{lll}
\multicolumn{3}{c}{ Realization of miracles by the Power of Jesus $[5,6]$} \\
$\mathrm{C}_{1}$ & - & Endurance through prayer \\
$\mathrm{C}_{2}$ & - & Faith \\
$\mathrm{C}_{3}$ & - & Humility \\
$\mathrm{C}_{4}$ & - & Repentance \\
$\mathrm{C}_{5}$ & - & Obedience \\
$\mathrm{C}_{6}$ & - & Hearing the Word of God \\
$\mathrm{C}_{7}$ & - & Authority in the spiritual realm \\
$\mathrm{C}_{8}$ & - & God's Compassion \\
$\mathrm{C}_{9}$ & - & love
\end{tabular}

\section{$C_{1}-\quad$ Perseverance through prayer}

Perserverance is any undertaking, continued pursuit or prosecution of any business or enterprise begun. In theology, persistence means continuance in a state of grace to a state of glory.

\section{$C_{2^{-}} \quad$ Faith}

Faith refers to the trust one puts in God at all times. It is total surrender to God with complete belief, without any need for logical proof or material evidence. Faith brings us into a direct encounter with God and it demands placing our complete trust on Him.

\section{$C_{3^{-}} \quad$ Humility}

Humility is the prerequisite for honor (Prov 15:33; 18:12; 22:4; 29:23) and physical blessing (Psalm 37:11; Matt 5:5). Intimately associated with the fear of the Lord (Psalms 25:9 Psalms 25:12-14; Prov 15:33), it may provide the key to wealth and life (Prov 22:4); but even when blessings are postponed, a humble spirit is necessary (Prov 16:18-19; cf. Romans 12:14 Romans 12:16-17). It is the gateway to eternal life (Matt 5:3; 18:1-4), not necessarily a physical reward (5:10-12).

\section{$C_{4^{-}} \quad$ Repentance}

Repentance is a change of heart which infuses a deep sense of humility in people. Repentance brings about inner healing taking up the broken chains of communication with God and with one another on a solid foundation.

\section{$C_{5^{-}} \quad$ Obedience}

Obedience refers to being ready to subject ourselves to the commands, wishes and guidelines of others. Obedience teaches us to deny ourselves and prompts us to act in

\section{$\mathrm{C}_{6}$ - Hearing the word of god}

The Bible claims to be the Word of God and by staking this claim the Bible simply but plainly declares its divine authority, complete infallibility and absolute sufficiency.

\section{$\mathrm{C}_{7 .}$ Authority in the spiritual realm}

The authority that the lord gives to his church-spiritual authority(not in the natural realm but spiritual.

\section{C $_{8^{-}}$God's compassion}

It simply says that compassion means sympathetic consciousness of others' distress along with a desire to alleviate it.

\section{C.-Love}

Love urges us to diffuse its fragrance on others love triggers off an emotional response leading to action.

\subsection{The Directed Graph related to study on miracles is given below}

$$
\mathrm{E}=
$$

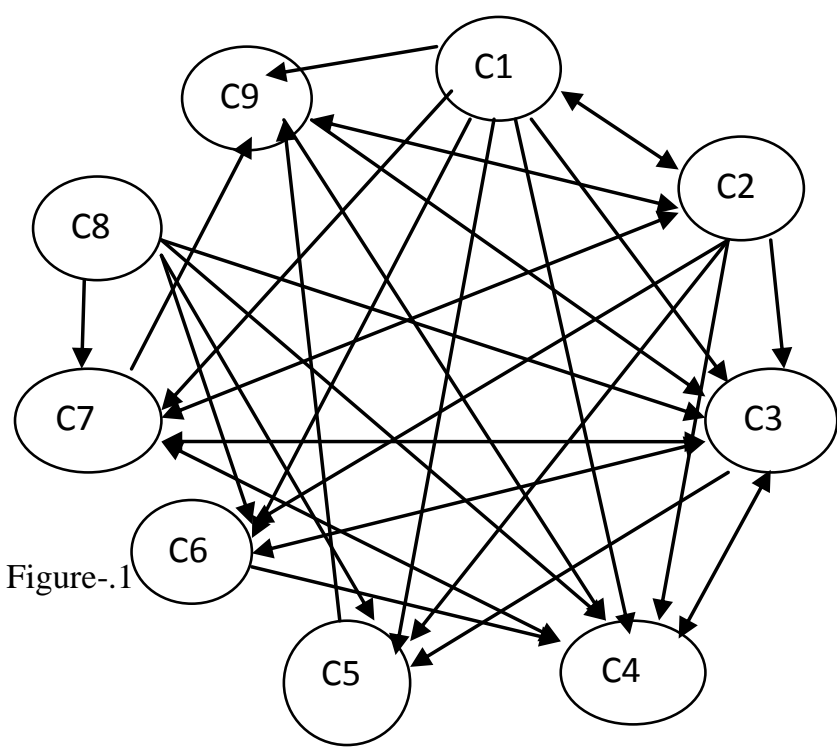

Figure -1 gives the directed graph with $\mathrm{C}_{1}, \mathrm{C}_{2}, \ldots, \mathrm{C}_{9}$ as nodes and figure- 2 gives the neutrosophic directed graph with the same nodes.

The connection matrix $E$ related to the graph in Figure-1. is given below 


$$
E=\left[\begin{array}{lllllllll}
0 & 1 & 1 & 1 & 1 & 1 & 1 & 0 & 1 \\
1 & 0 & 1 & 1 & 1 & 1 & 1 & 0 & 1 \\
0 & 0 & 0 & 1 & 1 & 1 & 1 & 0 & 0 \\
1 & 0 & 1 & 0 & 0 & 0 & 1 & 0 & 0 \\
0 & 0 & 0 & 0 & 0 & 0 & 0 & 0 & 1 \\
0 & 0 & 1 & 1 & 0 & 0 & 0 & 0 & 0 \\
0 & 1 & 1 & 1 & 0 & 0 & 0 & 0 & 1 \\
0 & 0 & 1 & 1 & 1 & 1 & 1 & 0 & 0 \\
0 & 1 & 1 & 1 & 0 & 0 & 0 & 0 & 0
\end{array}\right]
$$

According to this expert opinion, if $\mathrm{c} 1$ will be the on state then $c 8$ is absent in such a scenario ,the state victor gives the point.

Now we reformulate a different format of the questionnaire where we permit the expert to give answers like the relation between certain nodes is indeterminable or not known. Now based on the expert's opinion also about the notion of indeterminacy we obtain the following neutrosophic directed graph:[6]

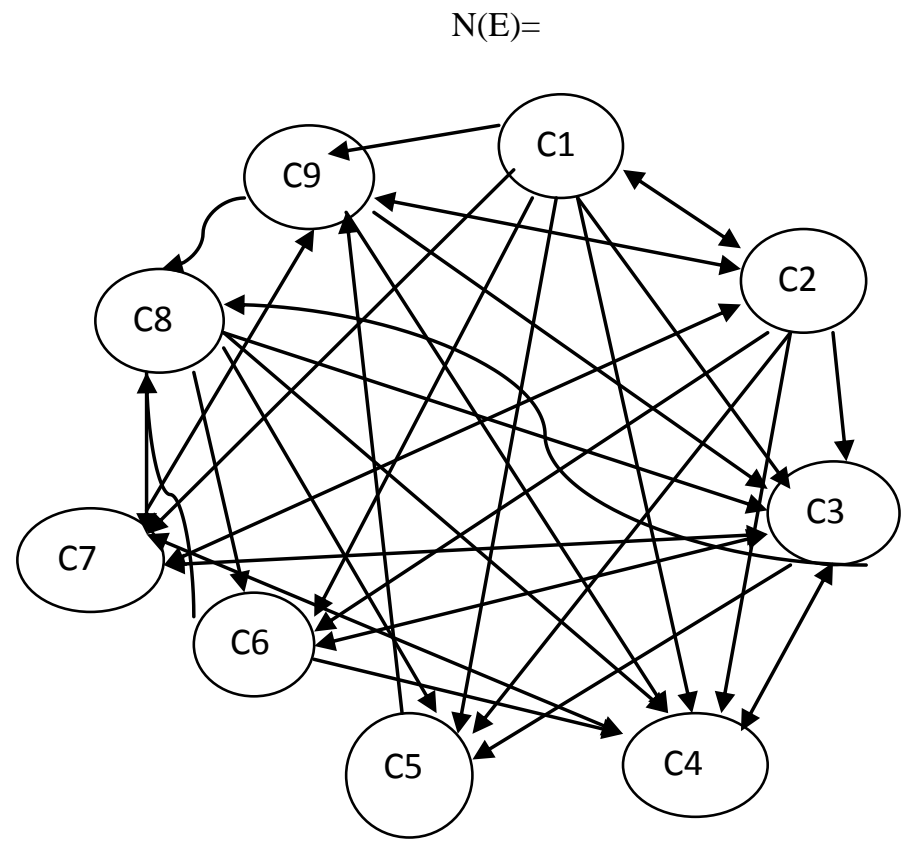

Figure-2

The corresponding neutrosophic adjacency matrix $N(E)$ related to the neutrosophic directed graph is given below

$$
N(E)=\left[\begin{array}{lllllllll}
0 & 1 & 1 & 1 & 1 & 1 & 1 & 0 & 1 \\
1 & 0 & 1 & 1 & 1 & 1 & 1 & 0 & 0 \\
0 & 0 & 0 & 1 & 1 & 1 & 1 & I & 0 \\
1 & 0 & 1 & 0 & 0 & 0 & 1 & 0 & 0 \\
0 & 0 & 1 & 1 & 0 & 0 & 0 & I & 0 \\
0 & 1 & 1 & 1 & 0 & 0 & 0 & 0 & 1 \\
0 & 0 & 1 & 1 & 1 & 1 & 1 & 0 & 0 \\
0 & 0 & 0 & 1 & 0 & 0 & 0 & 0 & 0 \\
0 & 1 & 1 & 1 & 0 & 0 & 0 & I & 0
\end{array}\right]
$$

Suppose we take the state vector

$$
A_{1}=\left(\begin{array}{lllllllll}
1 & 0 & 0 & 0 & 0 & 0 & 0 & 0 & 0
\end{array}\right) \text {. We will }
$$

see the effect on $\mathrm{E}$ and $\mathrm{N}(\mathrm{E})$.

$$
\begin{aligned}
& A_{1} E=\left(\begin{array}{lllllllll}
0 & 1 & 1 & 1 & 1 & 1 & 1 & 0 & 1
\end{array}\right) \rightarrow A_{2} \\
& A_{2} E=\left(\begin{array}{lllllllll}
2 & 2 & 5 & 5 & 2 & 2 & 3 & 0 & 3
\end{array}\right) \\
& \rightarrow\left(\begin{array}{lllllllll}
1 & 1 & 1 & 1 & 1 & 1 & 1 & 0 & 1
\end{array}\right)=A_{3} \\
& A_{3} E=\left(\begin{array}{lllllllll}
2 & 2 & 6 & 6 & 3 & 3 & 4 & 0 & 4
\end{array}\right) \\
& \rightarrow\left(\begin{array}{lllllllll}
1 & 1 & 1 & 1 & 1 & 1 & 1 & 0 & 1
\end{array}\right)=A_{4}
\end{aligned}
$$

Therefore $\mathrm{A} 3=\mathrm{A} 4$.

But God's compassion is absent in such a scenario .

Now we find the effect of

$$
\begin{aligned}
& A_{1}=\left(\begin{array}{lllllllll}
1 & 0 & 0 & 0 & 0 & 0 & 0 & 0 & 0
\end{array}\right) \underset{\text { on }}{N(E)} . \\
& A_{1} N(E)=\left(\begin{array}{llllllllll}
0 & 1 & 1 & 1 & 1 & 1 & 1 & 0 & 1
\end{array}\right) \rightarrow A_{2} \\
& A_{2} N(E)=\left(\begin{array}{llllllllll}
2 & 2 & 5 & 5 & 2 & 2 & 3 & 3 I & 3 I
\end{array}\right) \\
& \quad \rightarrow\left(\begin{array}{llllllllll}
1 & 1 & 1 & 1 & 1 & 1 & 1 & I & 1
\end{array}\right)=A_{3} \\
& A_{3} N(E)=\left(\begin{array}{llllllllll}
2 & 3 & 6+I & 6+I & 3+I & 3+I & 4+I & 3 I & 4
\end{array}\right) \\
& \quad \rightarrow\left(\begin{array}{lllllllll}
1 & 1 & 1 & 1 & 1 & 1 & 1 & I & 1
\end{array}\right)=A_{4} .
\end{aligned}
$$

Therefore A3=A4.[7]

Thus according to this expert opinion, "God's compassion leads to miracles according to the Bible. This mainly gives the indeterminate relating to God's compassion ,c1 to c9 become on state.

\section{Advantages of this method (N.C.M)}

1. NCMs measure not only the existence of causal relation between concepts or the absence of causal relations between two concepts but also gives

representation to the indeterminacy of relations between any two concepts.

2. We cannot apply NCMs for all unsupervised data. NCMs will have meaning only when relation between at least two concepts $\mathrm{Ci}$ and $\mathrm{Cj}$ are

indeterminate. 
3.The class of FCMs is strictly contained in the class of NCMs. (All NCMs can be made into FCMs by replacing I in the connection matrix by 0 ).

4. The directed graphs in case of NCMs are termed as neutrosophic graphs.i.e. in the graph we have at least two edges which are related by the dotted lines, means the edge between those two vertices is an indeterminate.

5. All connection matrices of the NCM are neutrosophic matrices i.e. they have in addition to the entries $0,1, .1$, the symbol I.

6. The resultant vectors i.e. the hidden pattern resulting in a fixed point or a limit cycle of a NCM can also be a neutrosophic vector; i.e. signifying the state of certain conceptual nodes of the system to be an indeterminate i.e. it is not off i.e. .0. not on i.e.' 1 ' and indeterminate relation is signified by I.

7. Because NCMs measure the indeterminate, the expert of the model can give due careful representation while implementing the results of the model.

8. In case of simple FCMs, we have the number of instantaneous state vectors to be the same as the number of resultant vectors but in case of NCMs we see the number of instantaneous state vectors is from the set $\{0,1\}$ where as the resultant vectors are from the bigger set $\{0,1, \mathrm{I}\}$. This is also one of the major differences between NCMs and FCMs.

\section{CONCULSION}

While analyzing FCM and NCM in FCM, the concept $\mathrm{c} 8$ is in the off state ,the other concepts $\mathrm{c} 1, \mathrm{c} 2, \mathrm{c} 3, \mathrm{c} 4, \mathrm{c} 5, \mathrm{c} 6, \mathrm{c} 7$ and $\mathrm{c} 9$ is on state, where as in NCM the concepts $\mathrm{c} 1, \mathrm{c} 2, \mathrm{c} 3, \mathrm{c} 4, \mathrm{c} 5, \mathrm{c} 6, \mathrm{c} 7, \mathrm{c} 9$ is on state but $\mathrm{c} 8$ is in the inderminate position. However, the results by FCM shows that God's compassion is requried for miracles, but the results of NCM show that the God's compassion is the most important attribute according to the expert opinion from the Bible.

\section{Compassion}

To feel passion for someone, to enter sympathetically into their sorrow and pain. Compassion means to have mercy ,to have sympathy and pity. Psalm $86: 15$ says God is a compassionate and gracious God, slow to anger, abounding in love and faithfulness (Philippians 1:8). Compassion finds its source in God's compassion (James 5:11). In compassion, He has provided salvation and forgiveness (Luke 1:78).

Lamentations 3:22-23 says that like all of Gods attributes, His compassion is infinite and eternal, His compassions never fail, they are new every morning.

Psalms 145:8-9 says that the Lord is gracious and compassionate, slow to anger and rich in love. The Lord is good to all, He has compassion on all he has made.

Some of results given by experts on how God's compassion leads to miracles are given below:
1. The four thousand fed

2. Simon's mother-in-law

3. The crippled woman

(Matt 15:32-38, Mark 8:2)

4. The ear of malchus

Matt 8:14-17)

5. The impotent man

6. Leper

(Luke 13:10-17)

(Matt 26:47-56)

(John:5:1-18)

(Mark 1:41, Luke 5:12-16, Matt 8:2-4)

7. The man with dropsy

(Luke 14:1-6)

8. The widow's son raised

9. The man with a withered hand (Matt 12:9-14,

Mark 3 :1-6,Luke 6:6-11)

10. Healing the blind man

(Matt 20-34)

\section{Suggestions}

Kindly read the bible as it is a living book and a volume of vital power. It is seven fold in its nature and mandates the following:

(a) Conviction of $\sin$

(Acts 2:37)

(b) Regeneration of the heart

(1Peter 1:23)

(c) Instilling of faith

(Romans 10:17)

(d) Cleansing of life

(John 15:3)

(e) Edifying the Believer

(Acts 20:32)

(f) Imparting eternal life

(1 John 5:13)

(g) Perfection of the whole man

(2timothy $3: 17$ )

Abraham Lincoln said of the Bible: "This Great Book ... is the best gift God has given to man. All the good the Saviour gave to the world was communicated through this book. But for it we could not know right from wrong" (Speeches and Writings, 1859-1865 [1989], 628).

\section{ACKNOWLEDGMENT}

The authors wish to thank A. Praveen Prakash and C.Jayalatha, for the valuable support.

\section{REFERENCES}

[1] The Holy Bible -The bible society of india-ISBN81-2210246-8

[2] Axelrod, R.(1976). Structure of decision: The cognitive maps of political elites. Princeton, NJ: Princeton university press.

[3] Kosco, B."Fuzzy Cognitive Maps" International journal of man-machine studies, Januar y, (1986), 62-75

[4] Kosco, B., Neural Networks and Fuzzy Systems: A Dynamical Systems Approach to Machine Intelligence, Prentice Hall of India, 1997

[5] A Study on Miracles through Holy Bible using Combined Overlap Block Fuzzy Cognitive Maps (COBFCMS) A.Victordevadoss,A.Rajkumar,N.Jose parvin praveena ,International Journal of Computer Applications (0975 - 8887) Volume 53- No.15, September 2012.

[6] A Study on miracles through Holy bible using Induced Fuzzy Cognitive Maps (IFCMS A.Victordevadoss,A.Rajkumar,N.Jose parvin praveena , International Journal of Computer Applications (0975 - 
8887) Volume 54-No.15, October 2012.

[7] Vasantha Kandasamy W.B and Smarandachel Florentin 'Fuzzy Cognitive Maps and Neutrosophic Cognitive Maps', Xiquan, Phoenix (2003)

[8]Vasantha Kandasamy W.B and Smarandache Florentin"Analysis of Social aspects of Migrant labourers living with HIV/AIDS using Fuzzy Theory and
Neutrosophic Cognitive Maps", Xiquan, Phoenix (2004).

[9] The text book of Fuzzy Cognitive Maps And Neutrosophic Cognitive Maps W. B. Vasantha Kandasamy,Florentin Smarandache 